\title{
Trajetória socioprofissional da mulher na agronomia: uma questão de renda e da satisfação profissional
}

Teresa Daros Szöllösi tdaros@yahoo.com.br Universidade do Minho, Minho, Portugal

Maria Sara de Lima Dias msaradldias@gmail.com Universidade Tecnológica Federal do Paraná, Curitiba, Paraná, Brasil.

\section{RESUMO}

Este artigo é parte da pesquisa de mestrado: "Reflexões sobre a trajetória socioprofissional e o projeto de vida do egresso graduado em agronomia" na qual objetivou-se comparar a relação entre a trajetória de graduadas(os) no curso de Agronomia entre as décadas de1990 e 2000. Estudo embasado teoricamente na psicologia social comunitária, propicia reflexões sobre o espaço profissional da mulher na engenharia agronômica. Espaço considerado como uma vinculação a um processo coletivo de luta das mulheres por uma comunidade de profissionais. Trata-se de um estudo transversal, cuja metodologia é de cunho quantitativo e qualitativo, o instrumento utilizado foi um questionário eletrônico, desenvolvido para esta pesquisa, a coleta de dados foi realizada através do e-mail das (os) egressas (os) graduadas (os). A análise foi realizada por meio do teste de Qui Quadrado e Análise de Conteúdo. Os resultados mostram que houve um aumento significativo da quantidade de mulheres a se diplomar no curso de Agronomia na década de 2000. Evidenciou-se redução salarial, na segunda década, tanto para homens quanto para mulheres. Mas, a redução salarial das mulheres é ainda mais evidente se comparada com a dos homens. Quanto à satisfação no trabalho atual, verificou-se redução significativa deste sentimento entre os profissionais formados na década de 2000. A trajetória da mulher tem sido marcada pela percepção de que enfrentam um maior grau de dificuldade para conseguir emprego na área de formação. Tal quadro exige das políticas públicas uma maior preocupação para com a proteção ao trabalho da mulher engenheira agrônoma.
\end{abstract}

PALAVRAS-CHAVE: Trajetória socioprofissional; gênero; engenharia agronômica. 


\section{INTRODUÇÃO}

O presente artigo é parte de uma pesquisa de mestrado e se propõe a refletir sobre a abertura de espaço profissional para a mulher graduada em Engenharia Agronômica e assim permitir reflexões da trajetória profissional da mulher na engenharia agronômica. Considerando uma vinculação possível desta abertura do mercado de trabalho a um processo histórico de luta das mulheres. Este curso é historicamente visto como formador de uma carreira para o gênero masculino. 0 gênero, como um conceito, surgiu em meados dos anos 1970 e disseminou-se instantaneamente nas ciências a partir dos anos 1980, conforme Marlize Matos (2008). Procura-se ainda compreender como essa diferença entre as escolhas dos homens e das mulheres foi sendo construída ao longo dos anos a ponto de construir carreiras eminentemente masculinas e femininas.

O fato é que contemporaneamente as mulheres estão transformando seus lugares de trabalho em algo maior e cujo reconhecimento social deve ser evidenciado. O papel das lutas feministas envolvidas na garantia de direitos trabalhistas das mulheres permite mapear o poder global do gênero e suas conquistas conforme Maria Lugones (2008). Sabe-se, no entanto, que as escolhas têm grande participação da família e da rede social em que as pessoas estão inseridas. (DIAS, 2011).

O curso de Agronomia na Universidade Federal do Paraná (UFPR) foi frequentado inicialmente, por quase meio século, predominantemente por homens, sendo que a mulher somente toma parte desse espaço a partir das últimas décadas do século XX. (LUIZ; COSTA; COSTA, 2010). Vale lembrar que a designação do Curso na instituição de onde os sujeitos desta pesquisa são egressas(os) é Agronomia e que a titularidade obtida no diploma é Engenharia Agronômica.

O referencial teórico da psicologia social veicula uma determinada visão de homem e de mundo, ao partir do pressuposto que as pessoas constroem o social e ao mesmo tempo são produzidas por ele conforme Silvia Lane 2006). Deste modo as egressas(os) são compreendidas(os) como um ator social e que vivencia, na materialidade de sua vida, um período de transição entre a formação universitária e mundo do trabalho.

Existem diferenças significativas na divisão social do trabalho, operada pelo capital na percepção do aumento da força de trabalho feminino em diferentes campos de atuação profissional. (ANTUNES, 2009). Assim como diferentes visões entre os benefícios e malefícios do trabalho na percepção das (os) trabalhadoras (es), entre desempregadas (os) e empregadas (os), bem como entre desempregadas (os) à procura de um primeiro emprego e com experiência profissional prévia, assim como implicações a nível psicológico, social e institucional (PAULINO; COIMBRA; GONÇALVES, 2010).

A integração pelo trabalho e a inserção relacional formam um duplo eixo no qual o indivíduo pode ser situado. No que diz respeito à relação de trabalho, podem ser vistas três gradações: trabalho estável, trabalho precário e não trabalho. Da mesma forma, pode ser traçado um paralelo com o eixo referente à rede de relação social: inserção relacional forte, fragilidade relacional e isolamento social (ANTUNES, 2009). Da combinação dessas gradações duas a duas chegamos 
a três diferentes zonas, quais sejam, a zona de integração (trabalho estável e forte inserção relacional), a zona de vulnerabilidade (trabalho precário e fragilidade dos apoios relacionais) e a zona de marginalidade (ausência de trabalho e isolamento relacional). Historicamente, as mulheres se situam em zonas de vulnerabilidade ou marginalidade devido a sua condição social.

Para Karl Marx (1999) o trabalho é a mediação entre o homem e a natureza. Pelo trabalho o homem transforma a si e a natureza. Agindo sobre o mundo exterior e modificando-o, o ser humano transforma a si e ao seu meio. A Organização Internacional do Trabalho (OIT) (2013) no Brasil, afirma que 77,3\% da renda famílias brasileiras advêm do trabalho e ainda, segundo o Instituto Brasileiro de Geografia e Estatística (IBGE) (2014), obtém-se a informação de que 38\% dos lares brasileiros são chefiados por mulheres. Logo, o trabalho feminino precisa ser protegido, posto que esta expansão do trabalho feminino tem, entretanto, significado um terreno de desigualdades no campo salarial. (ANTUNES, 2009). A centralidade do trabalho, enquanto um processo social, exerce importante função no grau de insegurança vivido pelas mulheres graduadas. Para Pedro Fernando Bendassoli (2006) a vinda do capitalismo trouxe consigo a semelhança (a ligação) entre identidade e trabalho, tanto que hoje se usa o verbo "ser" tanto para se referir ao nome próprio quanto para se identificar profissionalmente.

O trabalho feminino no campo da engenharia agronômica tem suas especificidades também de localização geográfica e política. O Paraná comemora o fato de ocupar posição de destaque entre os estados brasileiros no que se refere à exportação no setor do agronegócio, "participando com 15,5\% do total nacional" (BRAUN; CARDOSO; DAHMER; RINALDI, 2012, p. 223). As empresas são atraídas por incentivos fiscais e se deslocam movidas por esse fator. "A política macroeconômica praticada desde 1990 leva à destruição de partes significativas da estrutura produtiva e do emprego sem estabelecer uma nova base de desenvolvimento, com forte apoio na geração de empregos" (POCHMANN, 1998, p. 1).

A mulher em sua identidade profissional se torna na divisão sexual do trabalho, algo mais completo e complexo. Assim, eventual revés na trajetória profissional por causa do gênero pode revelar se da maior importância, não raro sendo um dos principais motivos de muito sofrimento para a pessoa. É como se não fosse apenas o aspecto profissional que estivesse passando por uma crise, mas todo o ser. Portanto neste recorte da pesquisa objetivou-se ao comparar o perfil da engenheira agrônoma egressa de uma instituição pública de ensino, analisar esta dimensão de gênero. Cabe se perguntar como acontece a inserção feminina no mundo do trabalho nas últimas décadas, no campo da engenharia agronômica

\section{METODOLOGIA}

A partir da abordagem teórica da psicologia social foi realizada uma pesquisa de mestrado sobre o perfil da(o) egressa(o) do curso de agronomia. O Instrumento de pesquisa foi enviado para 1.446 egressas (os) ou graduadas(os) no Curso de Agronomia do Setor de Ciências Agrárias (SCA) da UFPR, pessoas que se diplomaram entre 1991 e 2010 e que estão filiados ao Conselho Regional de Engenharia e Agronomia do Paraná (CREA-PR). Neste artigo recorte da pesquisa 
serão apresentados e analisados somente os dados relativos à questão das egressas do curso de agronomia.

A metodologia de pesquisa é quantitativa e qualitativa. No procedimento quantitativo, a análise foi realizada por meio de testes estatísticos, ao passo que no procedimento qualitativo, as questões foram analisadas por meio da Análise de Conteúdo (BARDIN, 1995).

Como instrumento de investigação para esta pesquisa, foi criado um questionário com perguntas objetivas e abertas. Tal instrumento foi indicado para obtenção dos dados necessários aos objetivos elencados e devido ao elevado número de sujeitos (CROSBY, 2003, p. 67). Para validação do questionário, ele foi submetido a uma banca de juízas (es), engenheiras (os) diplomadas(os) em períodos diferentes ao da pesquisa propriamente dita, esta banca foi composta por 89 pessoas da turma de 2011do curso de Agronomia da UFPR.

As respostas enviadas pelo grupo davam acesso a uma ferramenta eletrônica de recepção e armazenamento dos dados e foi realizada a análise de confiabilidade do questionário por meio do cálculo de alfa de Cronbach (HORA; MONTEIRO; ARICA, 2010). Como resultado da avaliação, o instrumento obteve um valor de alfa de Cronbach ajustado de 0,83. Com este saldo, garantiu-se a confiabilidade do instrumento e iniciou-se a investigação propriamente dita.

Após a validação do instrumento, o CREA-PR enviou um convite para o e-mail dos sujeitos da pesquisa. Caso elas(es) tivessem interesse, deveriam clicar no link, o qual dava acesso ao Questionário. O caput do questionário explanava sobre a pesquisa, sendo acompanhado do Termo de Consentimento Livre e Esclarecimento (TCLE). Foram analisadas as respostas das 114 egressas(os) que aceitaram participar da pesquisa e responderam ao questionário. A pesquisa encontra-se protocolada no site da Plataforma Brasil e sua identificação pode ser feita tanto pelo título, quanto pelo número CAAE: 506671312.7.0000.0100. O parecer do Comitê de Ética em Pesquisa da Pontifícia Universidade Católica do Paraná, que aprova a realização da pesquisa, pode ser localizado por meio do número 220.021 com data de 15/03/13.

As pessoas que responderam ao instrumento, foram constituídas em dois grupos representado por duas décadas, formadas(os) entre 1991 e 2000 e entre 2001 e 2010. Os dados relativos às questões com categorias de respostas fechadas foram inicialmente analisados por meio de frequências absolutas e relativas. As variáveis quantitativas foram analisadas por meio de médias e desvios padrão.

Após a estatística descritiva, a distribuição das frequências das variáveis qualitativas foi comparada entre os dois grupos de conclusão de curso, sendo tal análise realizada por meio do teste de Qui Quadrado para independência. As variáveis quantitativas foram comparadas por meio do teste t para amostras independentes, após a conferência dos pressupostos de normalidade (Teste de Lilliefors) e homocedasticidade (Teste de Levène). Em todos os testes estatísticos, foi utilizado um nível de significância de 0,05 $(p<0,05)$.

Para efetuar a análise de conteúdo, foi feita a categorização (FLICK, 2009; LEGENDRE; LEGENDRE, 1983), que é o agrupamento das informações em função de suas características a um termo para materializar suas semelhanças ou 
diferenças e, assim, observar as respostas das/os egressas/os nos dois períodos da análise.

Nestas questões com respostas abertas, a pessoa pode se expressar redigindo de forma livre as respostas, com o intuito de classificar as redações, foram realizadas repetidas e amplas leituras do material (TRIVINOS, 1987), sendo posteriormente organizadas em uma grade de dupla entrada: os dados da abscissa, demonstrando a resposta dos sujeitos, e os dados da ordenada, explanando as categorias que emergiram das falas dos respondentes. Tal procedimento foi determinante para posterior análise de conteúdo, conforme a proposta de Laurence Bardin (1995).

Nos próximos parágrafos, será apresentado o levantamento de dados da década de 1990 e da subsequente e, em seguida, a comparação entre os dois períodos. As respostas dadas pelos(as) participantes e aqui elencadas configuram categorias empíricas provenientes da visão das pessoas. Ao longo do texto, as décadas as quais os grupos pertencem serão didaticamente designadas como 1 a $d$ e $2^{2}$ d, correspondendo a de 1990 e a de 2000 , respectivamente. Após cada fala no texto, será usada a letra $E$ e, em seguida, o no de ordem da resposta ao instrumento. Exemplo: (1a d E1) é a (o) egressa (o) da década de 1990 que respondeu primeiro ao questionário.

\section{RESULTADOS DA PESQUISA E DISCUSSÃO}

Vale lembrar que a pesquisa objetivou comparar décadas, no entanto os resultados nos possibilitam fazer uma digressão para as especificidades do gênero na pesquisa. As pessoas que responderam o questionário foram subdivididas em dois grupos: um grupo com 47 respondentes (de 1991 a 2000) e outro grupo com 67 respondentes (de 2001 a 2010). Assumindo a distribuição dos dados em um padrão de Qui Quadrado, utilizou-se um tamanho de efeito médio ( $T E=0,3)$, erro tipo I (alfa) e erro tipo II (beta) equivalentes a 0,08, sendo, dessa forma, possível verificar um poder de explicabilidade das respostas obtidas de 0,92 , ou seja, $92 \%$.

A maioria dos participantes de ambos os grupos era do gênero masculino $(77 \%$ e 63\%, respectivamente), sendo que participantes da primeira década apresentaram idade de $42+3 \operatorname{anos}^{1}$ e, da segunda década, $34+5$ anos. Ao comparar a frequência de gêneros dos formados nos dois períodos em análise, foi possível verificar que houve um aumento significativo da quantidade de mulheres na segunda década de avaliação, elevando-se de 23\%, observado em 1991 a 2000, para 37\%, em 2001 a 2010 ( $\left.x^{2}=8,27 ; p=0,004\right)$ (fig. 1). 
Gráfico 1 - Frequência relativa percentual de gêneros de formados em Agronomia nos períodos de 1991 a 2000 e 2001 a 2010.

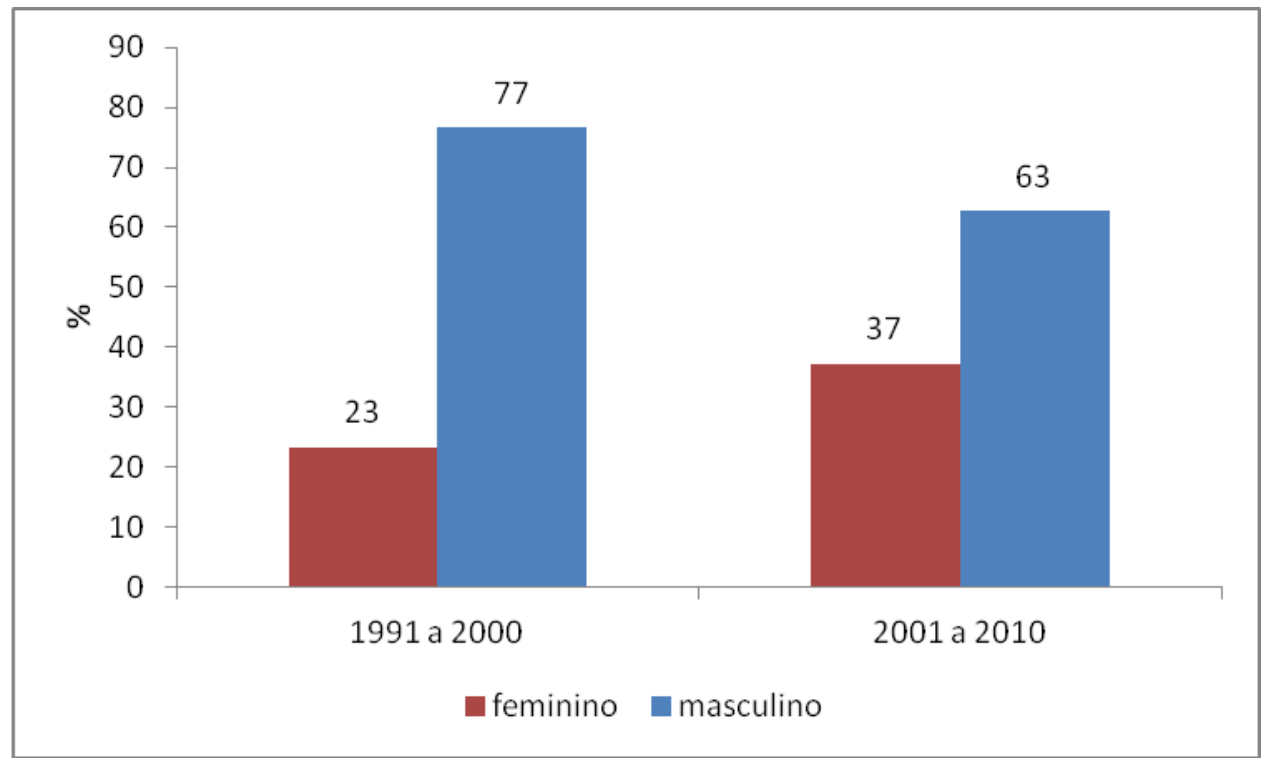

Fonte: dados da pesquisa - elaboração própria.

Ao observar historicamente os dados resultantes, o aumento do número de mulheres egressas no curso superior de engenharia agronômica pode ser analisado de diferentes formas que se confrontam dialeticamente. Por um lado, trata-se de um campo de lutas por direitos sociais que finalmente faz com que a mulher encontre seu espaço de trabalho na área da agronomia, por outro também é o resultado de uma composição de uma força de trabalho, com desigual percentual salarial respondendo aos interesses do capital intensivo (ANTUNES, 2009).

No campo da psicologia social, ao se analisar a identidade profissional, quando a mulher se apresenta "sou engenheira agrônoma (. . .)" (1ạd. E 30), ela não fala apenas de uma profissão, mas de uma inscrição na estrutura social. Ou seja, na atualidade, socialização e identidade estão baseadas no trabalho. A trajetória socioprofissional (DUBAR, 1997) das mulheres tem sido marcada por um amálgama entre a identidade profissional e a identidade pessoal, como se não fosse possível diferenciá-las ou até mesmo reverter esses dois elementos pelo fato de eles terem se tornado um terceiro.

E ainda por outro lado, não se pode negar que se trata de um movimento do capital para gerar mais valia e assim obter mão de obra qualificada para se beneficiar pagando-se salários menores, pois os salários mais altos são recebidos pelos homens (ANTUNES, 2013).

A perspectiva de gênero impacta no perfil da mulher egressa, uma vez que estão inseridas em um contexto econômico, cultural, social e histórico que disponibiliza ou não emprego para mulheres. A busca da mulher por inserção profissional em uma área tecnológica predominantemente masculina como na área da agronomia reflete alguns percalços, como nesta fala de uma egressa da primeira década (1a. d) que responde sobre as habilidades exigidas para atuar profissionalmente na área em que se graduou: "Teria que ser do gênero masculino para atuar" (1 $\mathrm{a}$ d E 4). Cumpre pontuar que todas as pessoas que responderam ao 
questionário da primeira ou da segunda década, estão vinculadas ao CREA-PR, poderiam estar trabalhando ou não na área no momento em que responderam ao questionário.

Portanto, ao analisar o perfil da mulher pesquisada nas décadas de 1990 e 2000, observa-se que, para enfrentar a transição da universidade para o mercado de trabalho, havia uma maior dificuldade de lutar contra o preconceito de gênero. Segundo Bendassoli (2006, p. 31), "na ausência de garantias institucionais ao trabalho, resta ao indivíduo responsabilizar-se por sua própria vida profissional", como nesta fala em que é conjugado o verbo trabalhar em primeira pessoa do singular "Eu nunca consegui trabalho na área de agronomia" (1ª. d E 79). Esta mulher concluiu a graduação em 2005 e até o momento em que foi realizada a pesquisa não conseguiu trabalho na sua área de formação. Dentre tantas consequências dessa divisão sexual do trabalho, uma destas é a frequência com que as graduadas não conseguem entrar no campo profissional, forjando uma identidade profissional incapaz de se concretizar.

Para Robert Castel (1998), a sociedade atual organizou-se de forma que a socialização está entrelaçada em torno do trabalho e a dificuldade para conseguir emprego e, consequentemente, a falta do mesmo pode gerar não apenas transtornos econômicos na vida do sujeito, mas também consequências emocionais. O aumento de profissionais que não trabalham na área demonstra um exemplo concreto da "subutilização de recursos humanos do país" (DOWBOR, 2002, p. 103). Ou seja, são profissionais com conhecimento técnico especializado que, apesar disso, não tiveram oportunidade de exercer sua profissão. $\mathrm{O}$ aumento de profissionais que não exercem a profissão para a qual se graduaram, ficando à margem, não podendo trabalhar com a agronomia, pode trazer a sensação de serem as/os inúteis do mundo (RIZEK, 1989), pois poderiam contribuir produzindo, participando da cadeia de produção de alimentos para a população e não tem espaço para colocarem isso em prática.

Ao avaliar a distribuição de frequências de grau de escolarização entre os gêneros das pessoas formadas entre o grupo 1á.p (1991 a 2000) e formadas do grupo 2a.p (2001 a 2010), foi possível verificar que na primeira década $37 \%$ dos homens faziam mestrado ou doutorado/pós-doutorado, enquanto $27 \%$ das mulheres alcançavam este grau de escolarização. Já na segunda década do estudo, apenas $19 \%$ dos homens chegaram a níveis de escolarização mais elevados, enquanto $44 \%$ das mulheres o fizeram (gráfico. 2). A relação entre a elevação do grau de escolarização feminina e o período histórico da formação, pode se dever a múltiplas razões, entre estas ao fato das mulheres estarem buscando maiores qualificações para poder adentrar ao campo de trabalho e ao fato de haver uma maior procura pela engenharia pelas mulheres no segundo período. 
Gráfico 2 - Graus de escolarização entre pessoas formadas e o gênero masculino e feminino, no período de 1991 a 2000 e 2001 a 2010.

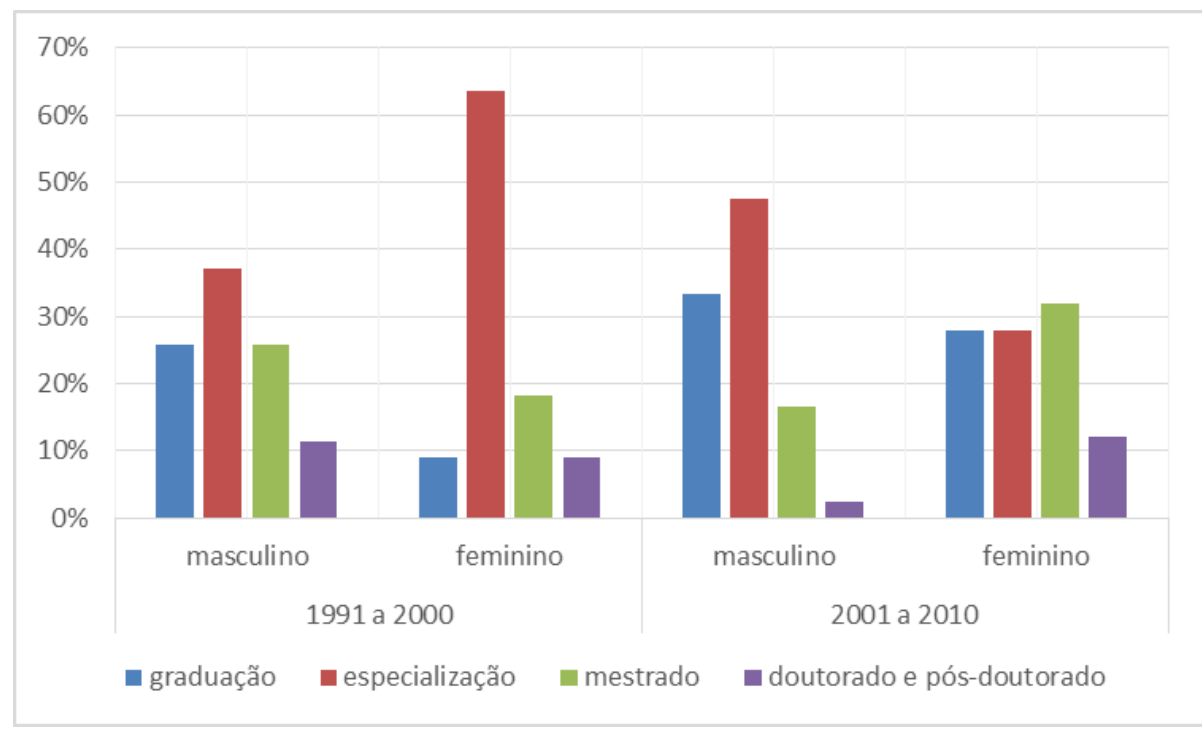

Fonte: dados da pesquisa - elaboração própria.

Esta associação exprime com clareza uma maior qualificação feminina para o trabalho, porém, não está diretamente relacionada a uma forma de salário equivalente ao do homem. Mesmo tendo maior qualificação as diferenças salarias ainda se mantém. Para Ricardo Antunes (2009) a ampliação do trabalho feminino no mundo produtivo é parte de um processo de emancipação parcial das mulheres, de inúmeras formas de opressão masculina. "Nessa nova lógica (. . . que legitima uma ampla reestruturação produtiva, onde os salários sofrem cada vez mais reduções e a educação emerge como 'salvadora' e principal ferramenta da atualização, o trabalho torna-se cada vez mais precário e seletivo" (HELOANI, 2005, p. 102).

Ao realizar a comparação da satisfação profissional em função do gênero e grau de formação, foi possível verificar que as(os) formadas(os) entre 1991 a 2000, relataram ter satisfação profissional independente do grau de escolarização $(p>0,05)$. Entre formadas(os) na década de 2001 a 2010, verificou-se que a satisfação entre as pessoas com diferentes níveis de escolarização ainda é semelhante $(p>0,05)$. Porém, ao se realizar o teste de acompanhamento de Marascuilo, verificou-se a tendência de ocorrer uma maior frequência de satisfação entre os respondentes com maior nível de escolarização, tanto no gênero masculino como no gênero feminino (tabela 1 e gráfico. 3). 
Tabela 1 - Satisfação no trabalho em relação ao gênero e nível de escolarização, entre as(os) formadas(os) nos períodos de 1991 a 2000 e 2001 a 2010.

\begin{tabular}{lcccc}
\hline & \multicolumn{2}{c}{1991 a 2000} & \multicolumn{2}{c}{$\mathbf{2 0 0 1}$ a 2010} \\
& Masculino & Feminino & Masculino & Feminino \\
\hline Graduação & $8(89 \%) a$ & $1(100 \%) a$ & $8(57 \%) a$ & $3(43 \%) a$ \\
Especialização & $13(100 \%) a$ & $7(100 \%) a$ & $14(70 \%) a$ & $3(43 \%) a$ \\
Mestrado & $7(78 \%) a$ & $2(100 \%) a$ & $6(86 \%) a b$ & $4(50 \%) a$ \\
Doutorado e pós-doutorado & $4(100 \%) a$ & $1(100 \%) a$ & $1(100 \%) b$ & $3(100 \%) b$ \\
\hline P & 0,283 & 1,000 & 0,513 & 0,355 \\
\hline
\end{tabular}

Fonte: dados da pesquisa - elaboração própria.

Gráfico 3 - Graus de satisfação com trabalho atual entre entrevistadas(os), com diferentes níveis de escolarização, formadas(os) no período de 1991 a 2000 e 2001 a 2010.

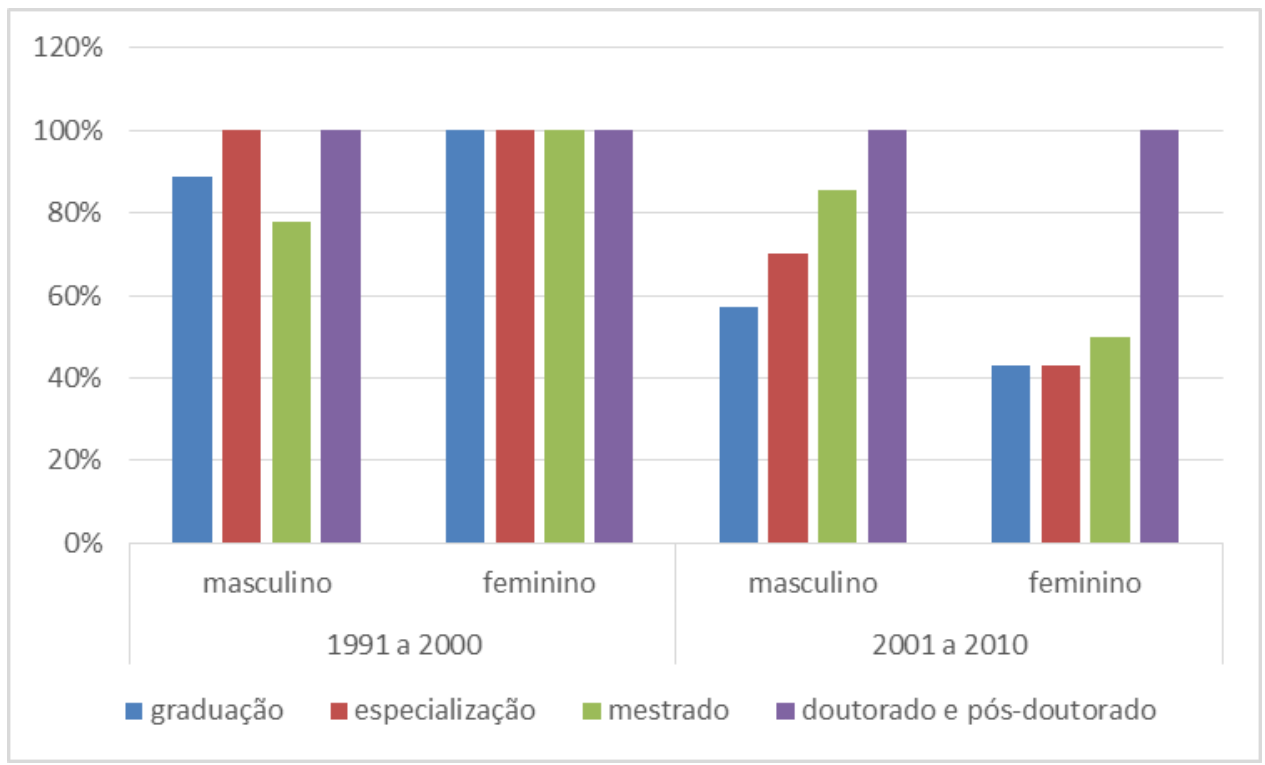

Fonte: Dados da pesquisa - elaboração própria.

Ao cruzar as variáveis de gênero e escolarização com o grau de satisfação no trabalho obtém-se um perfil no qual as mulheres formadas na primeira década, mesmo com mestrado, apresentam um elevado grau de satisfação em comparação com os homens da mesma década. Já na segunda década, o perfil das mulheres demonstra uma crescente diminuição de satisfação com o trabalho, representando uma exceção, no entanto, as participantes que concluíram o grau de doutorado. Corroborando estudos de Maria do Carmo Fernandes Martins e Gisele Emídio Santos (2006) sobre a satisfação com o trabalho para as mulheres.

As relações de gênero no universo do trabalho ainda são marcadas por importantes assimetrias, especialmente quando se trata do nível salarial e do acesso a posições de maior responsabilidade dentro das organizações. A percepção de desigualdade na distribuição e nos critérios de alocação de recompensas aplicados às mulheres influencia sua satisfação com o trabalho e sua 
identificação com a organização em que atuam. Além disso, verifica-se se o sentido do trabalho modera os efeitos da percepção de desigualdade de gênero sobre as atitudes das mulheres, intensificando-o entre aquelas para as quais a orientação para o trabalho está mais centralmente vinculada à sua identidade conforme Flávia de Souza Costa Neves Cavazotte, Lucia Barbosa de Oliveira e Liliana Carneiro de Miranda (2010).

Ao avaliar as classes de renda das(os) formadas(os) nos dois períodos em análise, foi possível verificar que houve diferenças estatísticas significativas entre

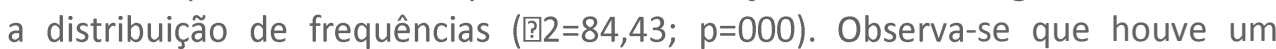
aumento significativo de formadas(os) na década de 2001 a 2010 que recebem de 1 a 3 salários mínimos (SM) e de 4 a $6 \mathrm{SM}(\mathrm{p}=0,05)$, assim, como a redução significativa daquelas(es) que recebem entre 7 a 10 SM e mais de 10 SM $(p<0,05)$ (gráfico. 4).

Gráfico 4 - Frequência relativa percentual das classes de renda das(os) concluintes do curso de Agronomia nos períodos de 1991 a 2000 e 2001 a 2010.

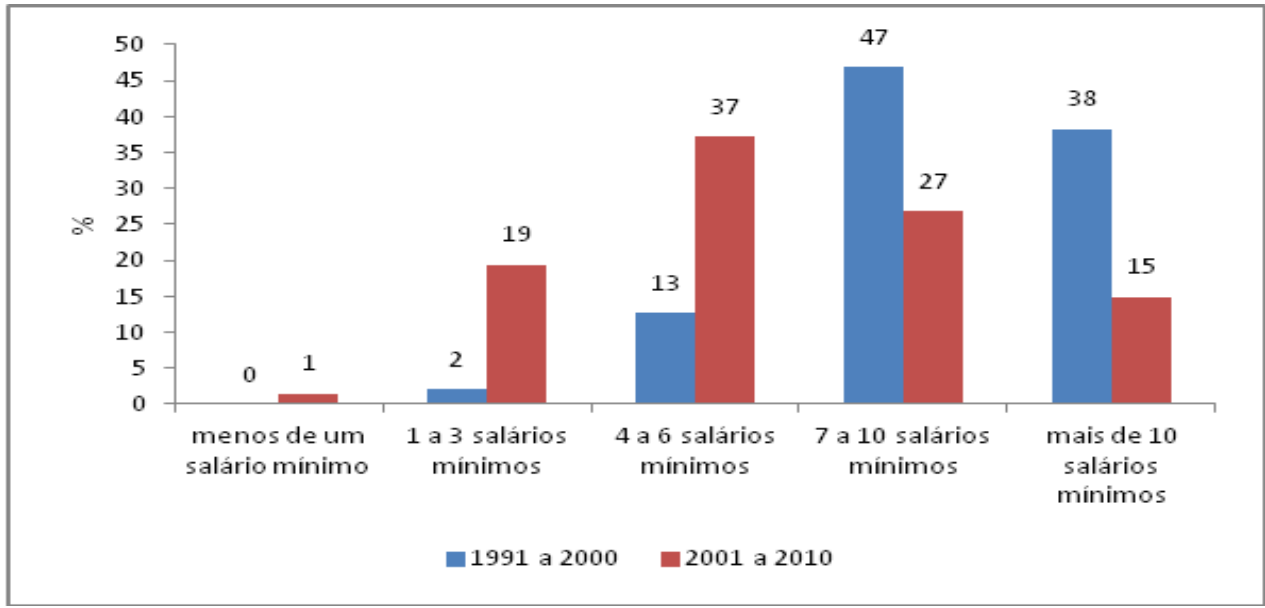

Fonte: dados da pesquisa - elaboração própria.

Verificou-se que a média salarial das(os) formadas(os) na década de 1991 a 2000 é de $R \$ 6.112,09$, enquanto a daqueles na década de 2001 a 2010 é de $R \$$ 4.147,56. Apesar do fato do menor período de trabalho ainda gerar uma menor renda, ressalta-se que ocorre uma redução significativa da renda das(os) profissionais mais recentes. Neste contexto, o diferencial de rendimentos entre homens e mulheres pode advir de, pelo menos, três causas: qualificações diferentes, inserções no mercado de trabalho diferentes ou um diferencial salarial puro (SOARES, 2000).

Cabe aqui uma observação quanto ao fato de as(os) engenheiras(os) agrônomas(os) estarem amparadas(os), desde o ano de1966, pela LEI No 4.950-A, que dispõe sobre a remuneração de profissionais diplomados(as) em Agronomia e fixa o salário-base mínimo em 6 vezes o maior salário-mínimo comum vigente no País (PLANALTO, 2013; CONFEA, 2013). Ou seja, o salário mínimo profissional é um direito da(o) engenheira(o) agrônoma(o), mas há um grande percentual de profissionais que ganham menos do que Ihes garante o Congresso Nacional. Além disso, houve um aumento no número de casos de descumprimento da lei a partir 
de 2000. É possível constatar que a(o) egressa(o) está ganhando menos com o passar do tempo.

Segundo Antunes (2013), o crescimento de profissionais que recebem salários menores ocorre devido ao aumento de oferta de profissionais qualificados(as). Aplicar o discurso do estado-mínimo e da menor ingerência do estado faz com que o capital tenha muito poder sobre o (a)trabalhador(a), e este acaba pagando uma conta que não é apenas sua, além de não poder colocar os seus sonhos em prática.

Para analisar a intensidade da diferença salarial entre o coletivo dos homens e mulheres, cruzam-se os dados conforme pode ser observado na tabela a seguir:

Gráfico 5 - Frequência relativa percentual de renda masculina e feminina dos concluintes do curso de Agronomia nos períodos de 1991 a 2000 e 2001 a 2010.

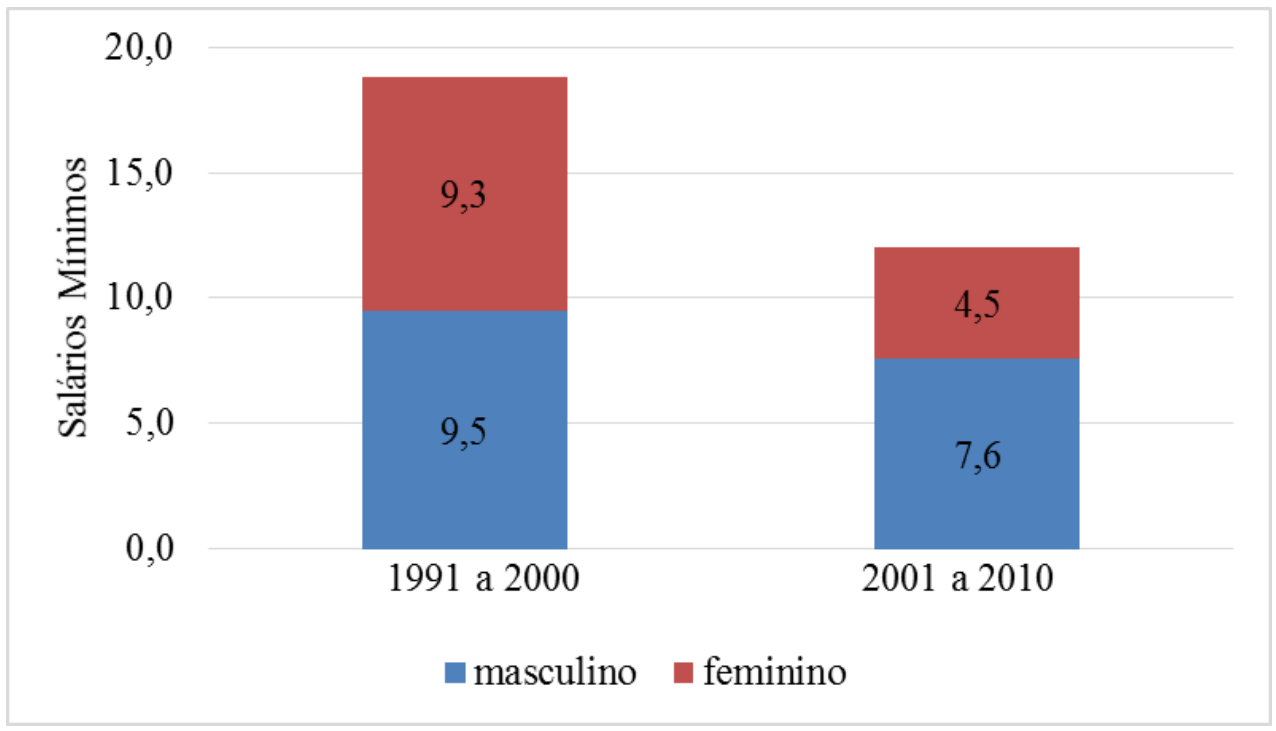

Fonte: dados da pesquisa - elaboração própria.

Há uma redução salarial, na segunda década, em relação à quantidade de salários mínimos tanto para homens quanto para mulheres. Mas, a redução salarial das mulheres é ainda mais evidente. Cabe aqui a observação de Antunes (2013), no que se refere às transformações do processo produtivo e aos reflexos no mundo do trabalho. A entrada da mulher no mercado de trabalho é uma resposta do capital à crise estrutural. $\mathrm{O}$ autor afirma que o aumento do trabalho feminino, de forma expressiva, no interior da classe trabalhadora, em escala mundial, é para suprir principalmente o espaço do trabalho precarizado, subcontratado e terceirizado. Ou seja, o aumento de alunas, na década de 2000, no curso de Agronomia, e a entrada da mulher no mercado de trabalho acabam sendo uma estratégia econômica para se pagar salários menores.

Os dados coletados apontam para a conclusão de que existe uma ausência de igualdade de remuneração entre gêneros, que pode ser demonstrada no gráfico 6 com as classes de renda, conforme segue: 
Gráfico 6 - Frequência relativa percentual das classes de renda masculina e feminina dos concluintes do curso de Agronomia nos períodos de 1991 a 2000 e 2001 a 2010.

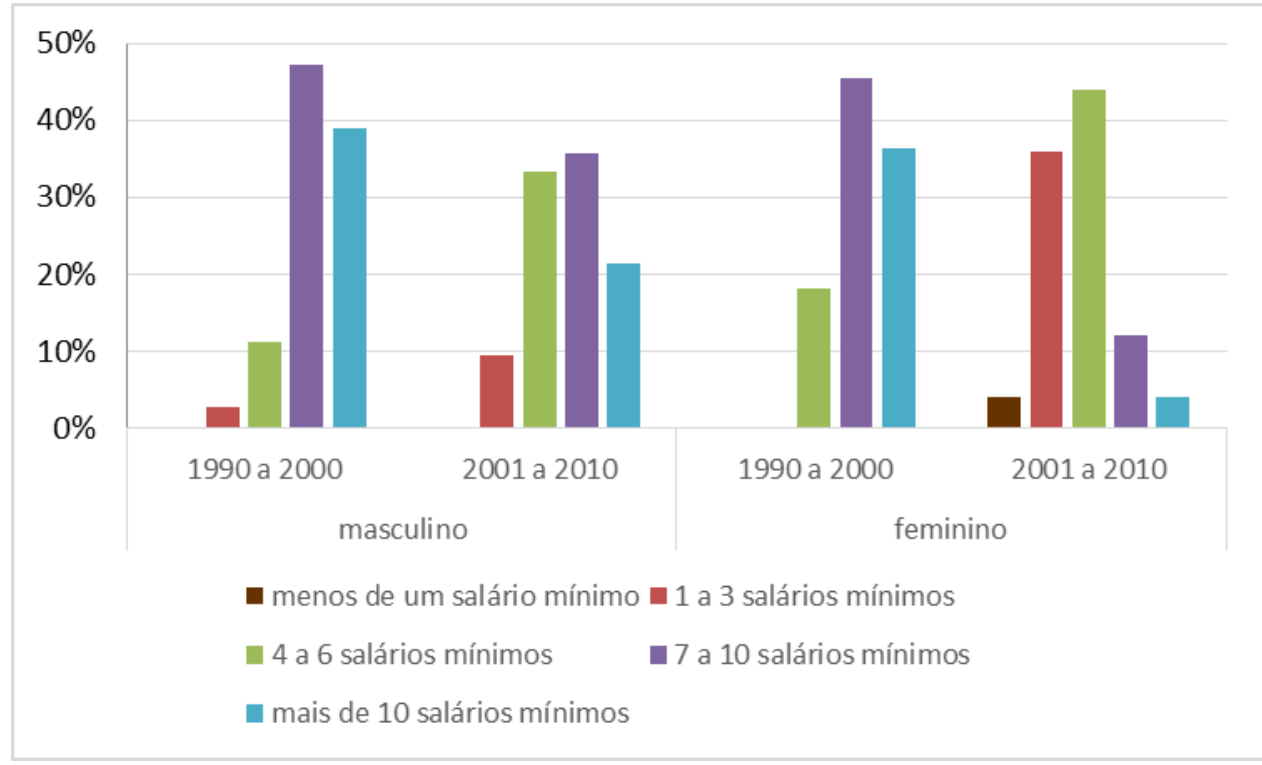

Fonte: dados da pesquisa - elaboração própria

O inventário do século XX tem como forte registro o protagonismo das mulheres em relação à alteração de seus lugares e posições sociais. Este é um lado da história, o outro, é o da permanência e da reprodução de elevadas desigualdades sociais entre os sexos, apesar da generalização das conquistas em termos de direitos políticos, civis e sociais em favor das mulheres. O mercado de trabalho se configurou como um lócus de análise que reflete as rupturas e continuidades nas desigualdades de gênero. (ARAúJO, 2013). No campo psicológico, a renda também pode estar relacionada a um sentimento de satisfação profissional com a atividade exercida. Deste modo, pesquisou-se quanto à satisfação no trabalho atual, verificando-se a redução significativa deste sentimento entre as(os) profissionais da década de 2001 a $2010 \quad\left(\chi^{2}=40,90\right.$; $p=0,000$ ), havendo a diminuição em $31 \%$ do observado entre os profissionais na década de 1991 a 2000 (gráfico. 7). 
Gráfico 7 - Frequência relativa percentual das pessoas formadas nos períodos de 1991 a 2000 e 2001 a 2010 e que apresentam sentimento de satisfação com o trabalho atual.

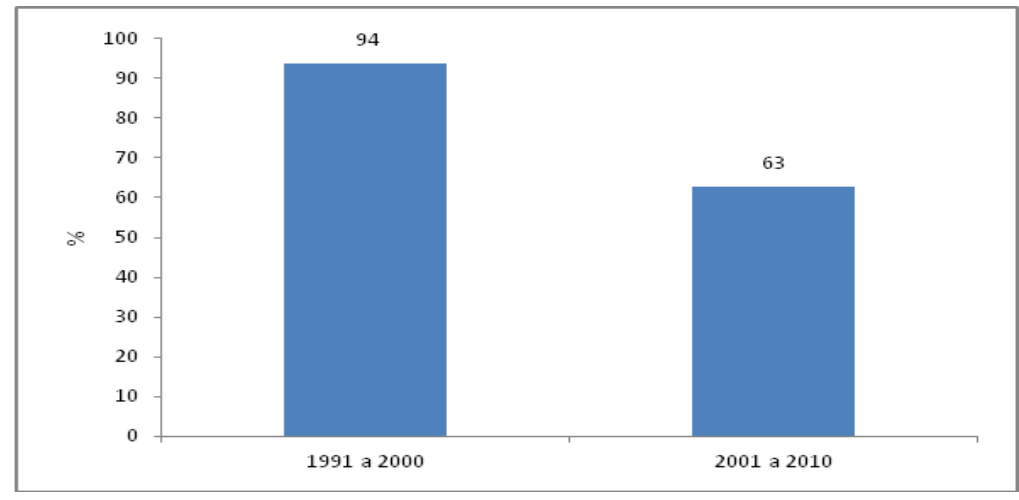

Fonte: dados da pesquisa - elaboração própria

Os dados de graus de satisfação foram avaliados em função do gênero e o período de formação dos sujeitos pesquisados. A satisfação foi comparada dentro de cada um dos gêneros, entre as pessoas formadas na 1a.e 2ª . décadas (períodos de 1991 a 2000 e 2001 a 2010), por meio do teste de Qui Quadrado para K proporções. Foi possível observar que entre as(os) formadas(os) na primeira década, praticamente todas(os) relataram satisfação com o seu trabalho, sendo observada a satisfação em $92 \%$ dos homens e 100\% das mulheres. Já entre as pessoas formadas na segunda década, observa-se uma queda significativa da satisfação com o trabalho, sendo que $52 \%$ das mulheres relataram-se satisfeitas com o trabalho $\left(x^{2}=7,92 ; p=0,005\right)$ e $69 \%$ dos homens relataram-se satisfeitos com seu trabalho $\left(x^{2}=6,083 ; p=0,014\right)$ (tabela 2 e gráfico 8 ).

Tabela 2 - Satisfação no trabalho em relação ao número total e do gênero no período.

\begin{tabular}{|c|l|c|c|c|}
\hline Gênero & Período de formação & Satisfação no trabalho & $\mathrm{n}$ & $p$ \\
\hline \multirow{2}{*}{ Feminino } & 1991 a 2000 & $11(100 \%)$ & 11 & \multirow{2}{*}{0,005} \\
\cline { 2 - 4 } & 2001 a 2010 & $13(52 \%)$ & 25 & \\
\hline \multirow{2}{*}{ Masculino } & 1991 a 2000 & $33(92 \%)$ & 36 & \multirow{2}{*}{0,014} \\
\cline { 2 - 4 } & 2001 a 2010 & $29(69 \%)$ & 42 & \\
\hline
\end{tabular}

Fonte: dados da pesquisa - elaboração própria

Podemos supor que, como fruto do processo de conscientização (FREIRE, 1979) e do papel da mulher no mundo do trabalho, houve uma redução entre as décadas de $48 \%$ do grau de satisfação, o que significa dizer que as mulheres estão se tornando mais críticas em relação ao seu trabalho, uma hipótese a ser aprofundada em pesquisas posteriores. O processo de estruturação de um estado neoliberal na década de 90 impactou no modo de gestão do trabalho na década seguinte ao promover uma maior fragmentação do trabalho, este fator, além disso, pode ter impactado no grau de satisfação das mulheres com o exercício profissional. Como nesta fala sobre a satisfação com o exercício profissional: "A formação em Agronomia, me proporcionou a base em Tecnologia dos Produtos Agropecuários, assim pude me especializar e trabalhar como pesquisadora nesta área." (2a d E 13). 
Se por um lado as mulheres se apresentam satisfeitas por terem atividades correlatas à profissão, por outro, a trajetória sócioprofissional também é marcada pela crise econômica. Enquanto no período 1940 a 1980, a População Economicamente Ativa (PEA) vive a incorporação de trabalhadores(as) no núcleo moderno da economia, os anos 1990 veem despontar a desestruturação do mercado de trabalho e o trabalhador vive o forte risco de exclusão do núcleo moderno da economia. Nesse contexto, Marcio Pochmann (1998) observa na PEA do Brasil, nos anos 90, três características: forte elevação do desemprego, movimento de des-assalariamento - eliminação dos empregos formais - e geração de ocupações precárias e de produtividade reduzida. Ou seja, apesar de haver empregadas (os) e desempregadas (os), para o empregado paira o fantasma do desemprego, fator que pode causar constante desconforto.

A agricultura moderna, tecnologicamente mais avançada, acaba por gerar menos emprego. "As inovações técnicas e organizacionais na agricultura concorrem para criar um novo uso da terra. $O$ aproveitamento de momentos vagos no calendário agrícola ou o encurtamento dos ciclos vegetais, a velocidade da circulação de produtos" (SANTOS; SILVEIRA, 2001, p. 118), também assim a caracterizam. Esse novo uso agrícola do território e o maior aproveitamento do tempo não trouxeram aumento da taxa de emprego, ou seja, a modernização da agricultura demonstra ser poupadora de mão de obra.

Para José Roberto Heloani (2005), as modernas formas de gestão no mundo atual, mundo este que passa por rápidas mudanças, desencadeadas pelo voraz processo de globalização, faz com que as organizações substituam a pessoa humana pela máquina. O uso de novas tecnologias, contudo, não pode ser apontado como a causa fundamental do desemprego, não pode ser visto isoladamente, conforme esclarece Margarida Barreto (2013).

A responsabilidade das demissões é atribuída às novas tecnologias, mas, na verdade, se for tirado o véu, percebe-se que ele esconde o processo crescente de desvalorização do trabalho e da vida das (os) trabalhadoras (es), assim como desvaloriza a formação para o trabalho. Esta relação entre período de formação e satisfação com o trabalho pode ser observada no gráfico a seguir: 
Gráfico 8 - Satisfação com trabalho atual entre pessoas formadas na 1a e 2a décadas.

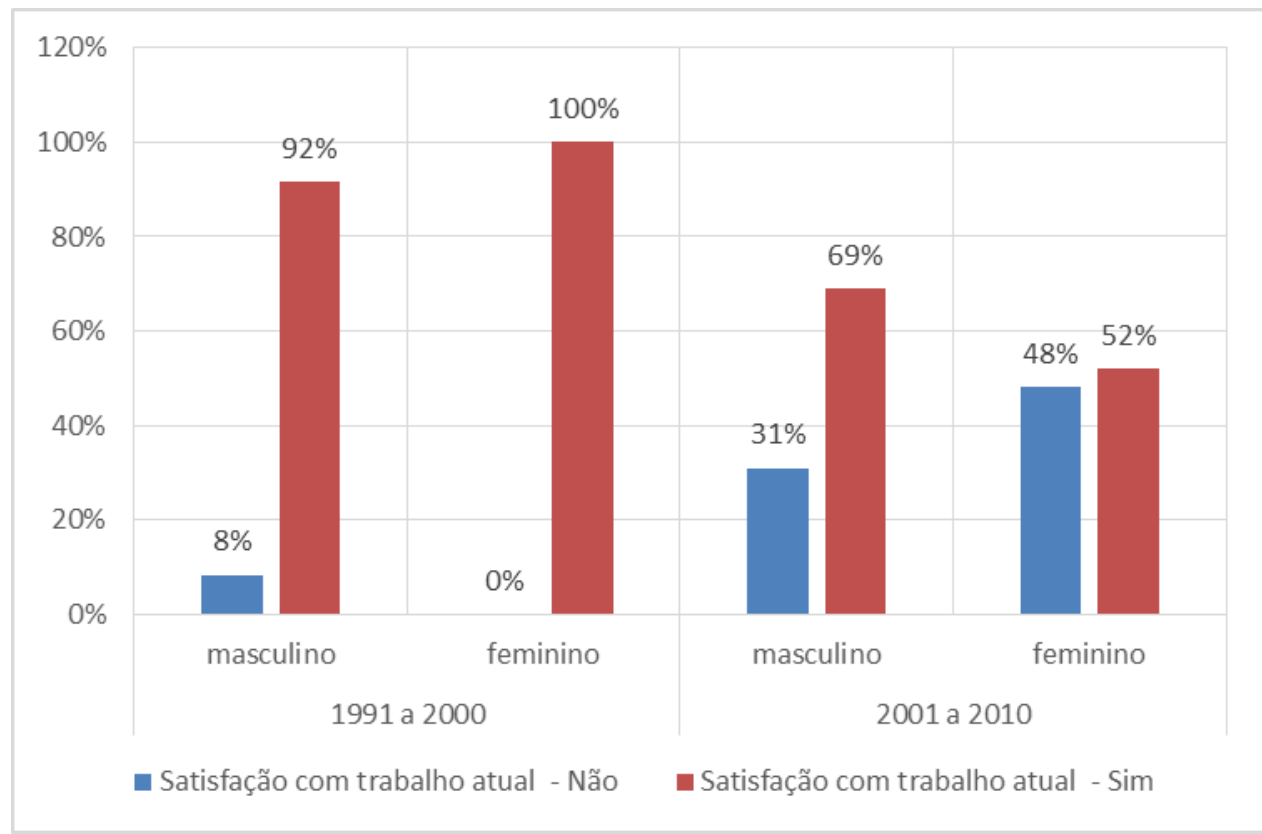

Fonte: dados da pesquisa - elaboração própria

Ao analisar o grau de satisfação, observa-se claramente a tendência dos histogramas de gênero por período de formação em haver o deslocamento dos mesmos à esquerda entre as(os) formadas(os) na 2a . década. Isso indica que entre este último grupo há uma tendência de apresentar graus de satisfação menores em relação ao seu trabalho, corroborando, portanto, com a análise apresentada anteriormente (gráfico 9).

Gráfico 9-Graus de satisfação com trabalho atual entre formadas (os) na 1ạ. e 2a. . décadas.

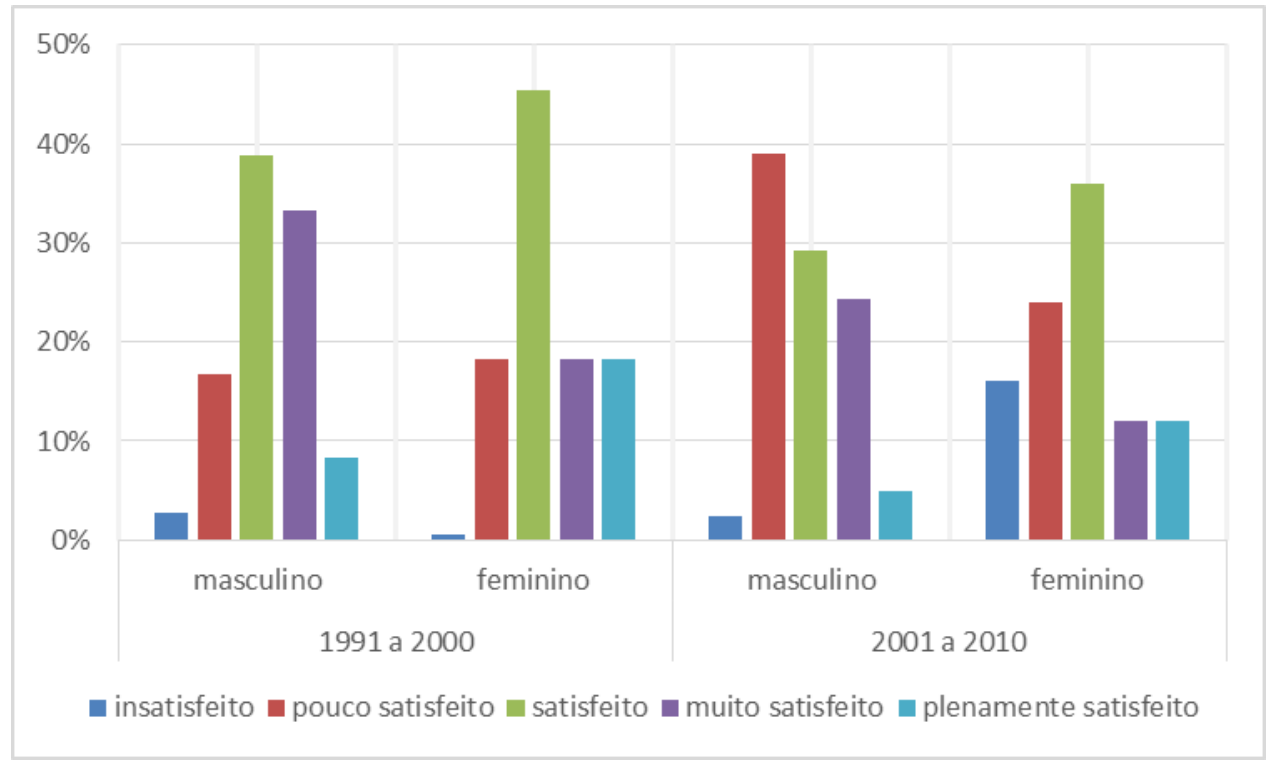

Fonte: dados da pesquisa - elaboração própria. 
As trajetórias profissionais estão marcadas por questões históricas permeadas pelo capitalismo vivido em um país que experimentou um período de regime militar de direita. Existe uma transição de um perfil das pessoas egressas que atendia a um projeto político nacional brasileiro de expansão da Agronomia e de fixação da(o) trabalhador(a) na terra para um projeto político nacional fruto da globalização, do avanço tecnológico, da abertura econômica e da representatividade do país na adesão ao projeto neoliberal no qual a informação e o conhecimento apresentam-se como elementos importantes para o crescimento da economia e que no momento vive a sua efervescência. (CASTELLS, 2002). Neste contexto o trabalho se modifica rapidamente e a educação e a formação se reduzem a uma possibilidade a mais para o sujeito entrar ou não no mercado de trabalho, sendo esta uma das características da trajetória profissional na sociedade contemporânea.

Para Castel (2005), as trajetórias profissionais hoje têm se tornado móveis, visto que a(o) profissional se desloca de um emprego para outro, não permanecendo longo tempo em uma mesma localidade de trabalho. Segundo Peter Berger e Thomas Luckmann (1998, p. 173), "estar em sociedade significa participar da dialética da sociedade".

$A(0)$ egressa(o) como um ser social vive as intempéries e benesses do momento social, econômico e político em que está inserido. Assim, na fala a seguir, a egressa desenha subjetivamente suas expectativas de projetos futuros e demonstra como se configurou seu sonho nas condições materiais de sua trajetória: "Meu projeto era trabalhar de agrônoma, mas mesmo mudando para o Mato Grosso, não encontrei colocação efetiva na área. Hoje trabalho de secretária num escritório de assistência veterinária. (. . .) (2 2 década, E 67). Para Bader Sawaia (2002, p. 98-99), "É no sujeito que se objetivam as várias formas de exclusão, a qual é vivida como motivação, carência, emoção e necessidade do eu. (. . .) É o indivíduo que sofre, porém, esse sofrimento não tem a gênese nele e sim em intersubjetividades delineadas socialmente".

Ao responder sobre a importância da formação para o trabalho na área, registrou-se a fala: "Não exerço atividade em Agronomia" (1a d E 107) ou ainda se evidencia aqui a mulher ao afirmar que a formação profissional não a ajudou para entrar no mercado de trabalho. Ocorre aqui a exclusão do seu campo de atuação profissional na Agronomia. Essa situação desencadeia as consequências abordadas por Sawaia (2002, p. 104-105), quando afirma que o sofrimento ético-político revela "a vivência cotidiana da desigualdade social, da negação imposta socialmente às possibilidades da maioria apropriar-se da produção material, cultural e social de sua época, de se movimentar no espaço público...". Trata-se de sofrimento ético-político, porque é imposto pelo social e reflete nas emoções, debilitando moral e fisicamente o sujeito, colocando-o profissionalmente como um apêndice inútil da sociedade. $\mathrm{O}$ ser sem trabalho fica diminuído na relação social. Confirma-se assim, concretamente, a visão de Castel (1998), quanto às condições de surgimento de uma situação marginal após esse duplo processo de desligamento, que envolve o trabalho e a rede social.

A disponibilidade e a flexibilidade são características solicitadas respectivamente para as pessoas da 1 a década e da 2 a década em sua função de engenheira(o) agrônoma(o). Sendo assim, seus desejos e vontades se concentram 
na produção. Barreto (2013) diz que o contexto atual de exigências crescentes e a pressão para produzir levam ao isolamento e, em consequência, ao aprisionamento cada vez maior da(o) mulher trabalhadora ao trabalho, de tal forma que não haja espaço ou tempo para tecer laços de camaradagem, resistência e luta. Para Heloani (2005, p. 101), "Novas tecnologias são implementadas nas empresas, o que obriga seus colaboradores a uma adaptação desumana, em busca de um novo perfil, ultracompetitivo".

Ao verificar as trajetórias sócio profissionais, surge a dimensão de gênero. Observa-se que, na 1a. década pesquisada, ao buscar uma oportunidade de trabalho, pertencer ao gênero masculino era uma exigência "Tinha que ter experiência em campo e ser homem" (1a d E 20). Tal pré-requisito já não aparece na última década pesquisada e a frequência de gêneros demonstra que houve um aumento significativo da quantidade mulheres agrônomas. A trajetória socioprofissional considerada como tipicamente masculina passa a se feminilizar (GOLDENBERG, 2005).

Diante das pressões que a vida contemporânea emana, a mulher exerce uma difícil conciliação entre o trabalho, a vida profissional e a vida em família, o que contribui diretamente para o aparecimento de novas formas de dominação e alienação em um mundo do trabalho que, contraditoriamente, exige excelência, conhecimento, aptidões, participação e entrega total da pessoa que trabalha.

Esse complexo de fatores toma forma nas respostas apresentadas na pesquisa, como a fala que considera que a formação profissional não Ihe auxiliou entrar no mercado de trabalho e justifica com o elemento da maternidade, conforme expressa: "Terminei o mestrado e tive um filho a pouco tempo, por isso estou em casa cuidando dele, mas logo pretendo retornar as atividades profissionais" (2 a d E 28). Constituir família aparece como um projeto, assim como aproveitar o convívio familiar e passar mais tempo com os entes queridos. Para Barreto (2013), o(a) trabalhador(a) disponível e flexível é aquele cujo tempo deve ser colocado à disposição do empregador na hora em que a empresa queira e necessite. Encontra-se despendendo, assim, o máximo de seu tempo para a empresa, enquanto ser que não tem tempo para a família e os amigos.

\section{CONCLUSÕES}

O Estado deve cumprir papel ativo na defesa dos diretos da mulher e lançar mão de estratégias para proteger a trabalhadora frente às imposições do mercado. Reveste-se de especial importância para as mulheres o perigo do desemprego, uma vez que grande parte dos lares brasileiros é chefiada por mulheres. A precariedade do trabalho feminino se revela através do fato de receberem salários menores que o dos homens.

Tal consideração é expressão da aplicação das práticas neoliberais, desta forma "a ofensiva do sistema financeiro acarretou reestruturações, desemprego, quebras de direitos sociais, reformas do contrato de trabalho, intensificação do trabalho e expansão da jornada, terceirizações e quarteirizações, flexibilização do contrato de trabalho caracterizando novas formas de precarização do emprego" (BARRETO, 2013 p. 14). 
Em razão da adequação do Estado às novas configurações da ideologia neoliberal, observa-se um saldo positivo no balanço dos rendimentos finais para o Estado, mas o emprego e o salário demonstram um movimento que the é inversamente proporcional. Esse saldo positivo deriva diretamente de um novo modelo adotado e não só o Estado do Paraná em si, mas também toda a região sul do Brasil, ganha com essa reestruturação do trabalho industrial no Brasil. Contudo, isso não se reflete na condição da(o) egressa (o), que ganha cada vez menos.

Houve uma configuração especial no mercado de trabalho que marca a trajetória socioprofissional da mulher graduada em Agronomia nas décadas de 1990 e 2000 que é vivida na materialidade do contexto neoliberal. Esta configuração com desarticulação de organizações coletivas e fortalecimento do individualismo parece ter tido efeitos positivos na satisfação profissional nas duas décadas em análise. Por um lado, essa trajetória é marcada pela diminuição de mulheres que trabalham na área de formação e pelo aumento do número daquelas que recebem salários menores do que o mínimo de direto da categoria, para além da crítica da profissão existe uma busca incessante por maiores qualificações no trabalho, e uma acirrada competividade que contribui para uma maior satisfação no trabalho, mesmo com baixa remuneração percebida.

O Estado precisa intervir na proteção do trabalho da mulher para que o trabalho seja dotado de dignidade e que corresponda às expectativas das pessoas na transição entre a educação e o trabalho. A universidade que se propõe a preparar para a vida profissional deve se preocupar com o perfil da mulher egressa de modo a responder às demandas da sociedade e do meio em que a (o) futura (o) profissional vier a ser inserida (o).

A mulher se expressa manifestando a sua satisfação profissional com o fato de seguir uma carreira almejada e, este posicionamento da mulher no mercado de trabalho vem alterando as trajetórias profissionais que de longa data eram exclusividade do mundo masculino.

Tal fato nos permite fazer um balanço sobre o aumento considerável do trabalho da mulher na área tecnológica. As instituições de ensino superior vêm recebendo cada vez mais mulheres, mas a inserção no mercado de trabalho, no entanto, ainda apresenta percalços de uma trajetória marcada por um papel social da mulher que deve ser reconstruído. Os anseios pela constituição da família apontam para uma demora maior para a inserção ocupacional. A multiplicidade de papéis historicamente assumidos pela mulher faz com que sua identidade ocupacional seja protelada.

É extremamente significativo o perfil econômico e de rendimento da mulher no mercado de trabalho. Tal fato certamente pode apontar para uma submissão aos desmandos do capital. A depreciação do trabalho feminino corresponde a uma estratégia do mercado para diminuir os pisos salariais. Por outro lado, se observa a importância da escolaridade cada vez maior, resultando em perfis de profissionais altamente qualificadas(os) e pouco remuneradas(os).

A instituição de um piso para a categoria como no caso da agronomia não protege necessariamente a todas as pessoas que, ameaçadas pelo desemprego e temerosas de nunca atuar na área em que se formaram, acabam por aceitar baixos salários. 
A questão da percepção subjetiva da satisfação com o trabalho, no entanto é contraditória, as mulheres estão $54 \%$ mais satisfeitas com o trabalho na agronomia do que os homens. Em duas décadas pautaram-se diferentes comparações de perfil que nos permitem afirmar desvantagens com relação aos homens em termos de flexibilidade e deslocamentos em busca de emprego. Soma-se a isso a característica de as mulheres estarem mais suscetíveis a abrirem mão de seus trabalhos em função da família.

A escola, enquanto instituição formadora, deve contribuir para uma reflexão crítica do papel social da mulher na economia do pais. Esta escola formadora para a sociedade pode até não antever as mudanças do mercado, mas pode capacitar seus educandos para serem sujeitos de direitos e não somente sujeitos de deveres. Ao problematizar a inserção da mulher no mercado de trabalho de uma forma crítica e construtiva, a instituição formadora pode contribuir para a garantia de seus direitos sociais como, por exemplo, o direito à isonomia salarial.

Ainda que existam políticas públicas de proteção ao trabalho da mulher que tenham favorecido os seus direitos como direito à licença maternidade e à amamentação, ainda existe um longo caminho de conscientização da sociedade sobre o papel da mulher no trabalho. Paralelamente, deve-se alcançar um resgate dos valores humanos da própria mulher, que deve fazer valer os seus direitos legais. Aceitar um trabalho por uma remuneração baixa também está relacionado com a alienação histórica do(a) trabalhador(a) o que resulta em considerar, muitas vezes, um trabalho precário e mal remunerado como satisfatório. Por isso a recuperação de uma memória histórica das lutas da mulher supõe a reconstrução de certos modelos de identificação que lhes abrirão o horizonte para sua libertação e realização (BARÓ, 2011).

Os resultados da pesquisa demonstram deste modo uma maior inserção da mulher na profissão de agronomia, mas contraditoriamente esta inserção acontece seguida também de salários menores. Logo, é ilusório pensar que já é uma conquista uma vez que ainda precisa ser muito ampliada para que as mulheres recebam um salário equivalente ao dos homens. O papel da mulher em nossa sociedade deve ser questionado desde o seu fazer cotidiano, e o seu papel social de trabalhadora que deve refletir uma ampla consciência seus direitos sociais. 


\title{
What have you done doing for being a woman? Report of an experience
}

\begin{abstract}
The objective of this report of experience is to present an analysis on the testimonies of women who somehow related to the UTFPR, campus Curitiba, in the month of March 2016. The study was based on the panels produced in the intervention developed by the Nucleus of Gender and Technology - GETEC, during the "II Women's Month of UTFPR - Women Winning Challenges", where women (and some men) left their accounts answering the following question: "What have you stopped doing for being a woman? The reports of these people, especially women (students, teachers, administrative techniques, outsourced workers, among others) were analyzed about their personal and institutional experiences, seeking to highlight their opinions and interpret their speeches under the gender lens. In a second moment, we present the statements made with the organizers of the intervention to capture their impressions about the impacts of the activity, by categories. Based on this analysis, it was possible to perceive the need for women to find spaces in which they can express their opinions, express themselves freely and spontaneously, spaces in which they can say what they really think about being women and the consequences of this Fact has in their lives. The intervention showed the need to create spaces that more often enable this dialogue within the university.
\end{abstract}

KEYWORDS: Gender relationships. Women. Dialogue spaces. Stereotypes. 


\section{NOTAS}

${ }^{1}$ Explicando $42(+3)$ significa: a média de idade é 42 anos com um desvio padrão 3 , sendo este um padrão para redigir resultados estatísticos.

\section{REFERÊNCIAS}

ANTUNES, Ricardo. Os sentidos do trabalho: ensaios sobre a afirmação e a negação do trabalho. São Paulo: Boitempo, 2009.

ANTUNES, Ricardo. As dimensões da crise no mundo do trabalho. O olho da história. Revista de história contemporânea. N.4, 2013. Disponível em http://www.oolhodahistoria.ufba.br/04antune.html. Acesso em 31 de out. de 2013.

BARÓ, Ignacio Martín. El Latino Indolente. In: Baró, I. M.. Psicologia de la Libertación. Madri: Ed. Trotta, 1998.

BARDIN, Laurence. Análise de conteúdo. Lisboa: Edições 70, 1995.

BARRETO, Margarida. Assédio moral: trabalho, doenças e morte. Lima C. B. (org.). Seminário compreendendo o assédio moral no ambiente de trabalho. São Paulo: Fundacentro, 2013. Disponível em http://www.assediomoral.ufsc.br/files/2013/03/Seminario-Combate-AMTFundacentro- 2013.pdf

BENDASSOLLI, Pedro Fernando. Os ethos do trabalho sobre a insegurança ontológica na experiência atual com o trabalho / São Paulo. Tese Doutorado do Programa de Pós-Graduação em Psicologia. Instituto de Psicologia da Universidade de São Paulo, 2006.

BERGER, Peter. L. \& Luckmann, Thomas. A Construção social da realidade: tratado de sociologia do conhecimento. Petrópolis: Vozes, 1998.

BRAUN, Miriam Beatriz Schneider; Cardoso, Rubiane Daniele; Dahmer, Vanessa de Souza; Rinaldi, Rúbia Nara. Consolidação e perspectivas da agroindústria paranaense em relação ao mercosul: uma análise de 1999 a 2009. Revista paranaense de desenvolvimento, Curitiba, n.122, 221-240, jan./jun, 2012. em: Disponível em http://www.ipardes.pr.gov.br/ojs/index.php/cadernoipardes/issue/archive. Acesso em 10 de out. de 2013

CASTEL, Robert. As metamorfoses da questão social: uma crônica do salário. Petrópolis:Vozes, 1998.

CASTEL, Robert. A Insegurança Social: o que é ser protegido? Petrópolis: Vozes, 2005.

CASTELLS, Manuel. A sociedade em rede. 6.ed. São Paulo: Paz e Terra, 2002.

CAVAZOTTE, Flavia. de S. C. N., Oliveira, Lúcia Barbosa. de, \& Miranda, Liliana Carneiro. de. Desigualdade de gênero no trabalho: reflexos nas atitudes das mulheres e em sua intenção de deixar a empresa. Revista de Administração Da USP - RAUSP, 45(1), 70-83, 2010. 
CONFEA. Conselho Federal de Engenharia e Agronomia. O salário mínimo profissional, 2013. Dísponível em

http://www.confea.org.br/media/manualsalariominimo.pdf Acesso em 20 de out. de 2013.

COZBY, Paul. Métodos de pesquisa em ciência do comportamento. São Paulo:Atlas, 2003.

DIAS, Maria Sara de Lima. O projeto de vida: sentidos do trabalho futuro.Curitiba: Editora CRV, 2011.

DUBAR, Claude. A socialização: construção de identidades sociais e profissionais. Portugal: Porto, 1997.

Flick, U'vve. Desenho da pesquisa qualitativa. Porto Alegre: Artmed, 2009.

FREIRE, Paulo. Conscientização: teoria e prática da libertação: uma introdução ao pensamento de Paulo Freire. São Paulo: Cortez \& Mouraes, 1979.

GOLDENBERG, Mirian. Gênero e corpo na cultura brasileira. Psicologia Clínica, 2005. http://doi.org/10.1590/S0103-56652005000200006

HELOANI, José Roberto. Assédio moral: a dignidade violada. Aletheia, n.22, jul./dez, 2005.

HORA, Henrique Rego Monteiro da, Monteiro, Gina Torres Rego, \& Arica, José. Confiabilidade em questionários para qualidade: Um estudo com o coeficiente Alfa de Cronbach. Produto \& Produção, vol. 11, n. 2, p. 85 - 103, 2010.

LANE, Silvia Tatiana Maurer. A Psicologia Social e uma nova concepção do homem para a Psicologia. In Lane, S. T. M. \& Codo, W. (orgs.). Psicologia Social o homem em movimento. (8. ed.). São Paulo: Brasiliense, 1989.

LANE, Silvia Tatiana Maurer. O que é psicologia social. 22. ed. São Paulo: Brasiliense, 2006.

LEGENDRE, Pierre. \& Legendre, Louis. Numerical ecology. Amsterdam: Elsevier, 1983.

LUGONES, Maria. Colonialidad y género. Tabula Rasa, (9), 73-101, 2008.

LUIZ, Natália Mattos, COSTA, Aline Franco Da, \& COSTA, Helder Gomes. Influência da graduação em engenharia de produção no perfil dos seus egressos: percepções discentes. Avaliação: Revista da Avaliação da Educação Superior (Campinas), 15(1), 101-120, 2010.

Manual de publicação APA/ Americam Phychological Association. 6. ed. Porto Alegre: Penso, 2006.

MARTINS, Maria do Carmo Fernandes, e Santos, Gisele Emídio. Adaptação e validação de construto da Escala de Satisfação no Trabalho. Psico-USF (Impresso), 2006.

MARX, Karl. O capital. Livro I. 17. ed.. Rio de janeiro: Civilização Brasileira, 1999.

MATOS, Marlise. Teorias de gênero ou teorias e gênero? Se e como os estudos de gênero e feministas se transformaram em um campo novo para as ciências. 
OIT . Organização Internacional do Trabalho. 2013. Disponível em http://www.oitbrasil.org.br/content/trabalho-decente-promotor-dodesenvolvimento. Acesso em 16 de dez. de 2013.

PAULINO, Ana Raquel Soares, Coimbra, Joaquim Luís, \& Gonçalves, Carlos Manuel. Diplomados do ensino superior na transição para o trabalho: Vivências e significados. Revista Brasileira de Orientação Profissional, 11(2), 177-188, 2010.

POCHMANN, Marcio. Desestruturação do mercado de trabalho. Revista Teoria e Debate, ano 11, no 37, fev/mar/abr, 1998. Disponível em http://www.teoriaedebate.org.br/materias/economia/desestruturacao-domercado-de-trabalho Acesso em 04 de dez. de 2013.

PLANALTO . LEI No 4.950-A, DE 22 DE ABRIL DE 1966. 2013. Disponível em http://www.planalto.gov.br/ccivil_03/leis/L4950a.htm. Acesso em 14 de dez. de 2013.

RIZEK, Cibele Saliba. Prefácio. In: CASTEL, Robert. As metamorfoses da questão social: uma crônica do salário. Petrópolis: Vozes, 1998.

SANTOS, Milton. \& Silveira, Maria Laura. O Brasil: território e sociedade no início do século XXI. (3. ed.). Rio de Janeiro: Record, 2001.

SAWAIA, Bader. 0 sofrimento ético-político como categoria de análise da dialética exclusão/inclusão. In Sawaia, B. (org.). As artimanhas da exclusão: análise psicossocial e ética da desigualdade social. 4.ed. Petrópolis, RJ: Vozes, 2002.

SOARES, Serguei Dillon. O Perfil da Discriminação no Mercado de Trabalho Homens Negros, Mulheres Brancas e Mulheres Negras. IPEA Textos Para Discussão, 769, 6-6, 2000. Disponível em http://desafios.ipea.gov.br/pub/td/2000/td_0769.pdf

TRIVINOS, Augusto Nibaldo Silva. Introdução à pesquisa em ciências sociais: a pesquisa qualitativa em educação. São Paulo: Atlas, 1987.

Recebido: 29 ago. 2017

Aprovado: 06 nov. 2017.

Como citar:

SZÖLLÖSI, Teresa Daros; DIAS, Maria Sara de Lima. Trajetória socioprofissional da mulher na agronomia: uma questão de renda e da satisfação profissional. Cad. Gên. Tecnol., Curitiba, v. 10, n. 36, p. 5-27, jul./dez. 2017.

Correspondência:

Teresa Daros Szöllösi. Rua dos Funcionários, 1540, Cabral, Curitiba, PR. CEP 80035-050

Direito autoral:

Este artigo está licenciado sob os termos da Licença Creative Commons-Atribuição 4.0 Internacional. 